\title{
Aplicação de Metodologias Geofísicas para Estudo de um Conjunto Dique-Soleira em Rio Claro (SP)
}

Yára R. Marangoni, Luís G.F. D’Agostino, Frederico R. Sosnowski, Vagner R. Elis e Carlos A. Mendonça IAG-USP

\section{Copyright 2004, SBGf - Sociedade Brasileira de Geofísica}

Este texto foi preparado para a apresentação no I Simpósio de Geofísica da Sociedade Brasileira de Geofísica, São Paulo, 26-28 de setembro de 2004. Seu conteúdo foi revisado pela Comissão Tecno-científica do I SR-SBGf mas não necessariamente representa a opinião da SBGf ou de seus associados. E proibida a reprodução total ou parcial deste material para propósitos comerciais sem prévia autorização da SBGt.

\section{Resumo}

Os dados deste trabalho distribuem-se ao longo de um perfil de $4 \mathrm{~km}$, cujo centro coincide com o limite positivonegativo da anomalia aeromagnética do Projeto Botucatu (SP). Ao longo deste perfil foram coletados dados de gravimetria, magnetometria terrestre e caminhamento elétrico. Esse perfil é praticamente coincidente com um perfil aeromagnético do projeto Botucatu. Resultados preliminares da inversão separada dos sinais gravimétrico e magnetométrico sugerem uma região com maior densidade e susceptibilidade no centro do perfil, no limite positivo-negativo da anomalia aeromagnética. Em ambos os dados, também modela-se uma região anômala na porção Sul do perfil, com amplitude menor e valores um pouco menores nas constantes físicas. O caminhamento elétrico sugere um duto na parte central do perfil e material mais resistivo em subsuperfície, afundando em direção ao Sul. O conjunto de dados pode ser interpretado como sendo a assinatura geofísica de um dique que alimenta um sill de diabásio na borda Sul do dique.

\section{Introdução}

No início da década de 1980, o levantamento aeromagnético do Projeto Botucatu delineou várias anomalias localizadas, sendo que na região do Horto Florestal de Rio Claro - SP, borda da Bacia do Paraná uma dessas anomalias aparece associada a um afloramento de diabásio. O afloramento foi mapeado como um sill, porém a anomalia aeromagnética (fig. 1) sugere a presença de um dique, o que nos levou a fazer um estudo de detalhe na região.

Neste estudo foram realizados perfis de gravimetria e magnetometria terrestre em uma linha de aproximadamente $4000 \mathrm{~m}$, com estações a cada $50 \mathrm{~m}$. Ao longo da mesma linha foi realizado um perfil de caminhamento elétrico nos primeiros $2400 \mathrm{~m}$. Para posicionamento horizontal e altitude de alguns pontos ao longo do perfil usou-se sistema GPS.

Coletou-se amostras das rochas sedimentares presentes na área, representativas da Formação Corumbataí e que afloram ao longo do perfil. Amostras do diabásio, aflorantes no Horto Florestal de Rio Claro, distantes cerca de $1,5 \mathrm{~km}$ do perfil, também foram amostradas para determinar-se valores de densidade e susceptibilidade magnética com a finalidade de melhorar os parâmetros na inversão dos dados.

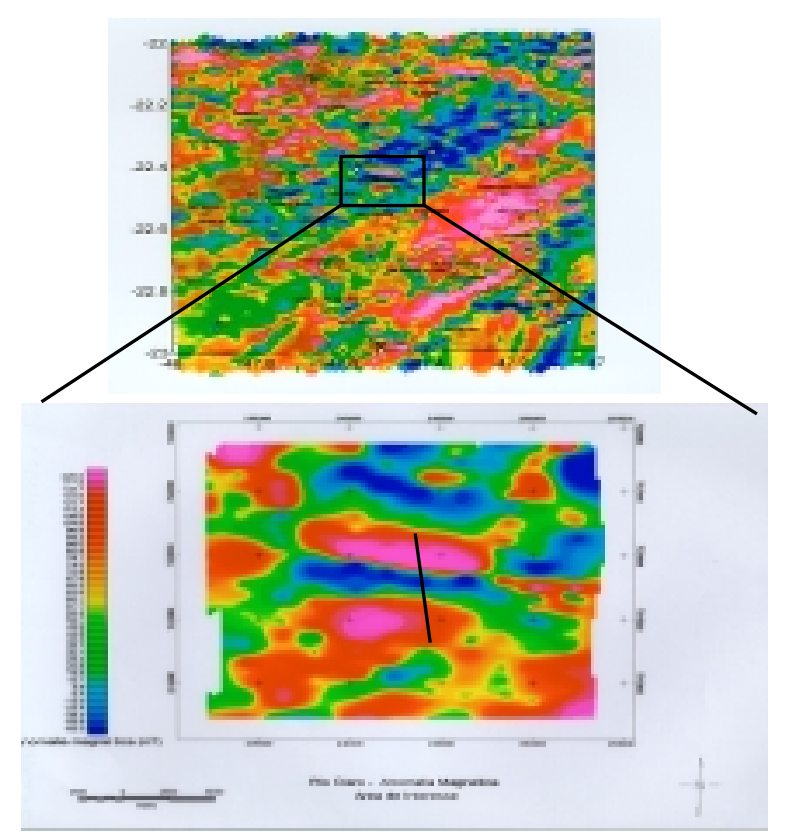

Figura 1 - anomalia aeromagnética da região de estudo e perfil.

Este trabalho tem por objetivo definir um modelo em subsuperfície para esse possível dique, considerando-o como fonte de alimentação de uma soleira de diabásio através da utilização conjunta de dados de gravimetria, magnetometria terrestre, aeromagnetometria e geoelétrica. $O$ estudo detalhado dessa anomalia servirá de teste para a extensão deste modelo para as feições aeromagnéticas similares evidenciadas pelo projeto Botucatu.

\section{Metodologia}

O perfil estudado foi marcado no terreno com estações intervaladas de $50 \mathrm{~m}$, de forma que o centro dele coincidesse com o limite positivo-negativo da anomalia aeromagnética. A topografia do terreno foi determinada com o uso de teodolito e apresenta precisão de centésimos de metro. Alguns pontos dentro do perfil foram rastreados com GPS de uma freqüência. No geral, a topografia apresenta erro de 2 a 3 metros com respeito ao nível do mar, e precisão interna do perfil de 0,05 m. 
O levantamento gravimétrico, realizado sobre o perfil (fig. 2), foi referenciado à base da UNESP de Rio Claro. Os dados foram reduzido usando o valor de $2,67 \mathrm{~g} / \mathrm{cm}^{3}$ para a densidade na correção de Bouguer e a Fórmula Internacional da Gravidade de 1967 para o cálculo da gravidade normal. Os valores de altitude foram os obtidos com o levantamento geométrico.
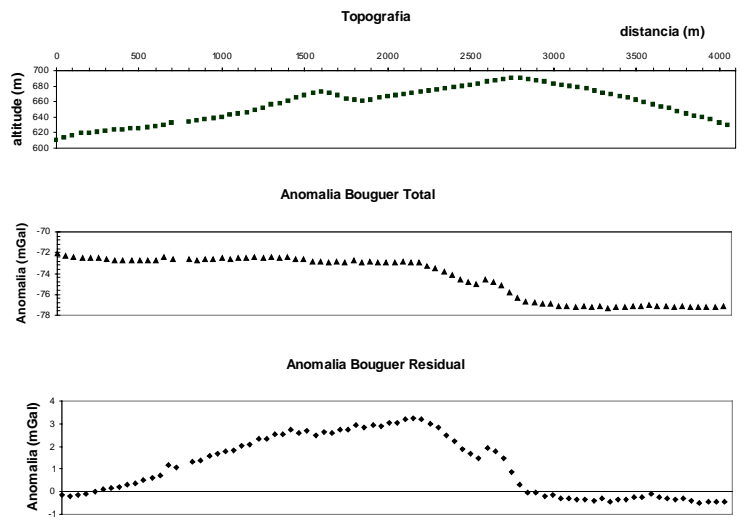

Figura 2 - perfil topográfico, anomalia Bouguer total e anomalia Bouguer residual. O início do perfil corresponde à parte Sul.

O levantamento magnetométrico (fig. 3), feito com dois magnetômetros overhouse, teve a variação diurna removida automaticamente. No centro da anomalia, onde o gradiente horizontal é mais intenso, o espaçamento entre os pontos diminuiu para 5 metros.

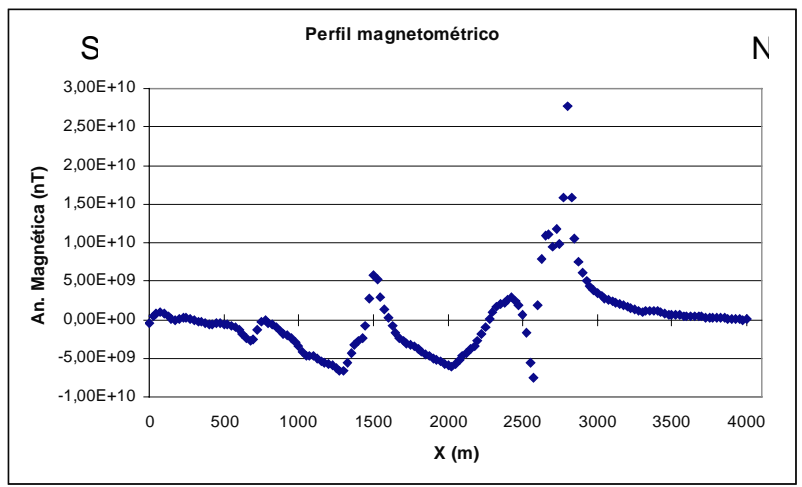

Figura 3 - Perfil magnetométrico.

A aplicação de ensaios de caminhamento elétrico com arranjo dipolo-dipolo possibilita que se construa uma imagem 2D de subsuperfície, na qual as variações laterais de resistividade e cargabilidade são relacionadas com contatos e outras estruturas geológicas. No presente trabalho o procedimento foi a aplicação de caminhamento com dipolo de 50 metros e 5 níveis de investigação. Para a realização das medidas de resistividade e IP domínio do tempo foi utilizado um conjunto transmissor TSQ-3 de $3 \mathrm{KW}$ de potência e um receptor IPR-12 digital, todos da Scintrex canadense.

\section{Resultados}

O perfil gravimétrico mostra valores mais negativos a norte, com variação de cerca $5 \mathrm{mGal}$. A anomalia residual foi removida usando o mapa de anomalia Bouguer de Zanão e Dourado (2003) do Horto Florestal de Rio Claro. O perfil deste trabalho está cerca de $1,5 \mathrm{~km}$ a leste do Horto e as anomalias gravimétricas não são tão pronunciadas como as do Horto. Um novo mapa com todos os pontos serviu para definir a separação regionalresidual. $O$ perfil residual mostra um alto de cerca 3 mGal na posição de $2400 \mathrm{~m}$ e um menor em cerca de $2600 \mathrm{~m}$. Nesse intervalo deve se localizar o dique de diabásio.

O perfil magnetométrico apresenta a maior variação na posição de $2600 \mathrm{~m}$ e um pico positivo na região de 1500 metros, onde a gravimetria também assinala uma pequena anomalia. Dos dados de campo total foi removido um valor constante de $23000 \mathrm{nT}$, que zera o perfil fora da região de interesse.

Os dados da resistividade foram interpretados com 0 programa RES2DINV de Loke (1998). O modelo 2D resultante é apresentado em isolinhas de resistividade e procura definir com maior precisão a posição e o formato das estruturas causadoras de anomalias. O resultado, apresentado (fig. 4), permite observar os altos valores de resistividade que caracterizam o corpo de diabásio dentro dos siltitos da Formação Corumbataí com menores valores de resistividade (< 40 ohm.m). Esse corpo apresenta-se como um sill que se estende das posições $350 \mathrm{~m}$ até 2.100 metros no perfil e entre as distâncias 2100 e 2200 metros o diabásio está disposto como um corpo vertical, caracterizando um dique que se comunica com o sill descrito. Na seção de cargabilidade não é possível observar claramente esses corpos, uma vez que tanto o diabásio como o siltito podem apresentar valores de cargabilidade de médios a altos.

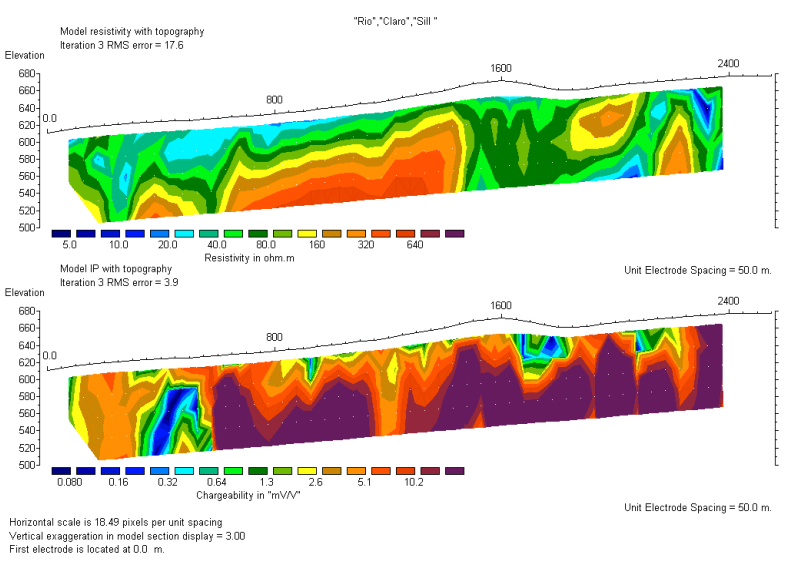

Figura 4 - Resultados da inversão das seções de resistividade e cargabilidade. 
Os valores da densidade das 47 amostras de diabásio, provenientes de 3 afloramentos diferentes, foram obtidos em laboratório através do Princípio de Arquimedes (um corpo imerso total ou parcialmente dentro de um fluido está sob ação de um empuxo igual ao peso do fluido deslocado). Estes encontram-se no intervalo de 2,8 a 3,0 $\mathrm{g} / \mathrm{cm}^{3}$, sendo o valor médio de $2,91 \pm 0,03 \mathrm{~g} / \mathrm{cm}^{3}$. Para as rochas sedimentares, além da densidade, pretende-se determinar a porosidade.

A inversão preliminar dos dados gravimétricos foi feita usando o programa MULTI (Barbosa et al. 1999, Silva et al. 2001). Este programa, que concentra a massa ao longo de eixos representando as maiores extensões do corpo em subsuperfície, usa como vínculos desigualdade, compacidade, proximidade absoluta e concentração no entorno dos elementos geométricos (Silva et al. 2001). Na figura 5 foram posicionados quatro eixos principais e a distribuição das massas sugere um corpo mais alongado horizontalmente, fragmentado em duas seções, com aproximadamente $2 \mathrm{~km}$ de largura e uma raiz inclinada entre $1,5 \mathrm{e} 2 \mathrm{~km}$. Os dados da magnetometria foram usados para delimitar horizontalmente o corpo de diabásio.
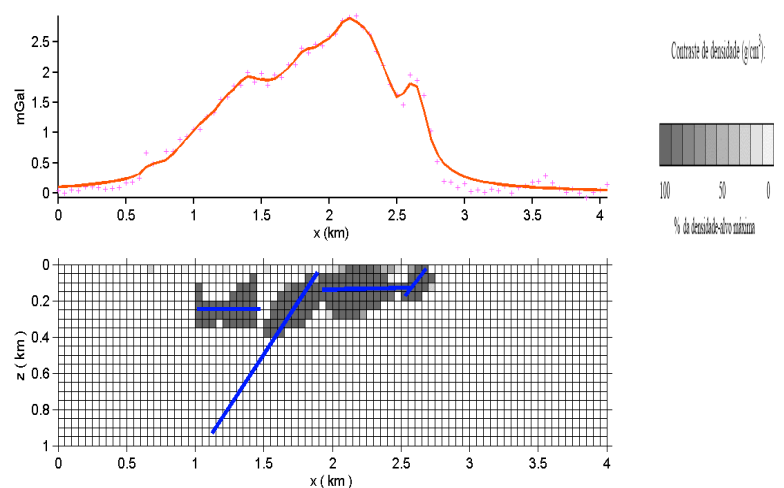

Figura 5 - inversão através da utilização de vários corpos.

Também foi feita a inversão separada do perfil gravimétrico e magnetométrico usando apenas o vínculo de suavidade. Os resultados (Fig. 6) mostram a presença de massa anômala, chegando até próximo da superfície, sob as posições de 1500 e 2400 metros. A inversão, usando apenas o vínculo da suavidade absoluta, mostra que o corpo anômalo parece ser contínuo em subsuperfície, abaixo dos $200 \mathrm{~m}$.

\section{Discussão e Conclusões}

Resultados preliminares da inversão separada dos sinais gravimétrico e magnetométrico sugerem uma região com maior densidade e susceptibilidade no centro do perfil, no limite positivo-negativo da anomalia aeromagnética. Com ambos os dados, também modela-se uma região anômala na porção sul do perfil, com amplitude menor e valores um pouco menores nas constantes físicas. A inversão usando apenas a suavidade mostrou a continuação dessa massa em subsuperfície (Fig. 6). Essa continuidade desaparece quando o vínculo de compacidade é introduzido (Fig. 5), embora os dois corpos modelados encontrem-se muito próximos. Em ambas inversões, nota-se uma região onde o corpo encontra-se mais profundo, entre os trechos de $1500 \mathrm{~m} \mathrm{e}$ $2000 \mathrm{~m}$, que também aparece nos resultados do caminhamento elétrico.

$\mathrm{S}$

$\mathrm{N}$
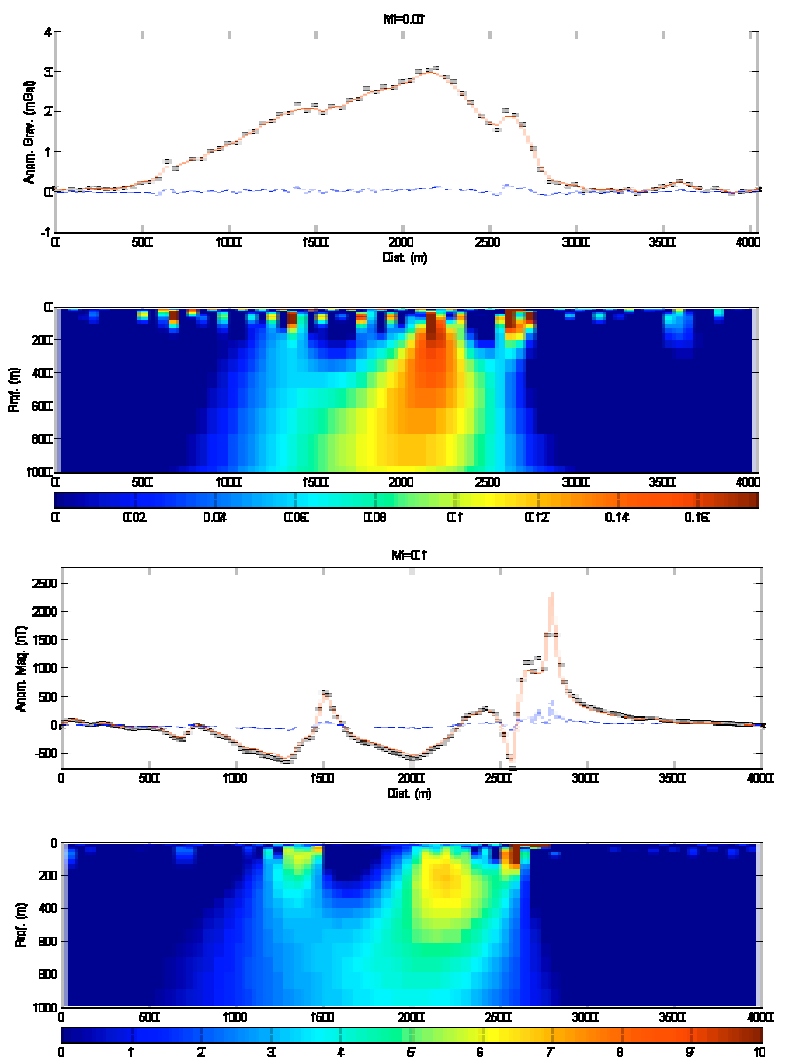

Figura 6 - Perfil gravimétrico e magnetométrico com suas respectivas inversões com vínculo de suavidade.

O conjunto de dados pode ser interpretado como sendo a assinatura geofísica de um dique que alimenta um sill de diabásio na borda sul do dique. Essa interpretação é compatível com a posição dos afloramentos de diabásio, as feições gerais da aeromagnetometria e do mapa de anomalia Bouguer do Horto Florestal. Dada a falta de assinatura gravimétrica e magnetométrica a norte do possível dique, pode-se inferir que este tenha alimentado uma soleira que desenvolveu-se a sul do mesmo em função da paleotopografia da região.

\section{Agradecimentos}

Agradecemos ao técnico Clarino Vieira, IAG-USP, e ao Dr. João Dourado, Unesp-RC, por colaborarem com as coletas de dados e amostras, e ao departamento de Geologia Aplicada da Unesp-RC pelo empréstimo de equipamentos. 


\section{Referências}

Barbosa, V. C. F., Silva, J. B. C. \& Medeiros, W. E., 1999, Stable inversion of gravity anomalies of sedimentary basins with nonsmooth basement reliefs and arbitrary density contrast variations: Geophysics, 64, 754-764.

Loke, M. H., 1998, RES2DINV ver. 3.3. for Windows 3.1 and 95. Rapid 2D resistivity and IP inversion using the least-squares method. Penang: M.H. Loke Software User's Manual, 35p.

Silva, J. B. C., Medeiros, W. E. \& Barbosa, V. C. F., 2001. Potential-field inversion: Choosing the appropriate technique to solve a geologic problem: Geophysics, 66, 511-520.

Zanão, R. \& Dourado, J. C., 2003, Estudo de um corpo de diabásio por meio da gravimetria. 8th International Congress of The Brazilian Geophysical Society held in Rio de Janeiro, Brazil, 14-18 September 2003. 